Peter Lugosi, Richard Robinson, Maria Golubovskaya, Laura Foley, Jan Harwell Experiencing parenthood, care and spaces of hospitality Sociological Review, 64 (2) pp. 274-293.

This version is available: https://radar.brookes.ac.uk/radar/items/e3d5a6a4-5ebd-43c9-85e5-af103e4a0182/1/ Available on RADAR: 22.07.2016

Copyright (C) and Moral Rights are retained by the author(s) and/ or other copyright owners. A copy can be downloaded for personal non-commercial research or study, without prior permission or charge. This item cannot be reproduced or quoted extensively from without first obtaining permission in writing from the copyright holder(s). The content must not be changed in any way or sold commercially in any format or medium without the formal permission of the copyright holders. 


\title{
Experiencing Parenthood, Care and Spaces of Hospitality
}

\author{
Dr Peter Lugosi ${ }^{\mathrm{a}^{*}}$ \\ Dr Richard N.S. Robinson ${ }^{\mathrm{b}}$ \\ Ms Maria Golubovskaya ${ }^{\mathrm{b}}$ \\ Ms Laura Foley ${ }^{\mathrm{b}}$ \\ Dr Jan Harwell ${ }^{\mathrm{a}}$
}

\author{
Published as: \\ Lugosi, P., Robinson, R.N.S., Golubovskaya, M., Foley, L. and Harwell, J. (2016) \\ Experiencing parenthood, care and spaces of hospitality. The Sociological Review, 64 \\ (2), 274-293, DOI: 10.1111/1467-954X.12330. \\ Please consult the final published version if citing. \\ ${ }^{a}$ Oxford Brookes University, United Kingdom \\ ${ }^{b}$ University of Queensland, Australia \\ ${ }^{*}$ Corresponding author \\ Contact: plugosi@brookes.ac.uk
}

\begin{abstract}
Drawing on research conducted in Australia and the United Kingdom, this paper explores how parenting and care provision is entangled with, and thus produced through, consumption in hospitality venues. We examine how the socio-material practices of hospitality provision shape the enactment of parenting, alongside the way child-parent/consumer-provider interactions impact upon experiences of hospitality spaces. We argue that venues provide contexts for care provision, acting as spaces of sociality, informing children's socialisation and offering temporary relief from the work of parenting. However, the data also highlight various practices of exclusion and multiple forms of emotional and physical labour required from care-providers. The data illustrate children's ability to exercise power and the ways in which parents'/carers' experiences of hospitality spaces are shaped by their enactment of discourses of 'good parenting'. Finally, we consider parents'/carers' coping behaviours as they manage social and psychological risks associated with consumption in such public spaces of leisure.
\end{abstract}

Keywords: Childcare; Consumption; Hospitality; Hospitality venues; Leisure; Parenting 


\section{Introduction}

For parents and those involved with child-care provision, consumption with children in public hospitality venues such as cafés and restaurants are undoubtedly multidimensional experiences in which notions of work, function and necessity are entangled with elements of escape, relaxation and pleasure. The complex and often contrasting experiences of parenthood and leisure, faced by women and men, have been explored by a number of authors (Davidson, 1996; Larson et al., 1997; Shaw, 1992), who demonstrated how women often continue to perform parenting duties during leisure consumption. More recently, there has been growing interest in family consumption of leisure when travelling, with particular emphasis on women's experiences (cf. Carr, 2011; Mottiar and Quinn, 2012; Schanzel et al., 2012). Researchers have also recognised that spaces of commercial hospitality are important sites in which family leisure and parenting are performed and brought into public domains; however, it is acknowledged that little is known about these everyday practices in restaurants, cafés and bars (Karsten et al., 2015; Lugosi, 2010).

This study addresses this gap in knowledge by considering parents' and carers' experiences of consuming with children in hospitality venues. Importantly, this study seeks to consider hospitality as context and also as a sensitising concept used to understand people's consumptive and social experiences. More specifically, beyond simply considering these venues as neutral or functional settings for food and drink consumption, utilising concepts from emergent hospitality studies enables us to be attentive to what happens in these spaces. Focusing on the nuances of hospitality provision forces us to be mindful of how the organisation of the consumption environment, transactions of food and drink, and encounters with staff and other consumers shape the parenting practices of those involved in care-provision. This includes how people's choices and behaviours may be constrained or facilitated in venues and why some venues, and spaces within venues, become inclusive and welcoming, while others are experienced as restrictive and unwelcoming.

Considering hospitality as a physical context for care provision and as a relational exchange between hosts and guests facilitates the conceptualisation of experiences in venues, contributing to knowledge in several ways. Firstly, it provides new insights into parents', particularly women's, experiences of hospitality spaces, including factors that make various spaces inclusive or exclusive. Secondly, it helps us to appreciate how those involved in 'doing' child-care manage specific aspects of their experiences during visits to venues. Thirdly, the study provides broader insights into experiences of parenthood and motherhood, including the multiple functions hospitality venues perform, sometimes offering relief from the stresses of parenthood, but often becoming part of the parenting process.

The paper begins by reviewing literature on parenthood, women's experiences of leisure, motherhood and consumption before considering hospitality as a conceptual underpinning for this study and its context. Following an examination of the study's methods, the results and discussion consider five thematic areas: the interaction of hospitality, parenthood and children's socialisation; hospitality as potential relief from the stresses of parenting; hospitality and the enactment of 'good 
parenting'; children's power; and finally, risks and coping behaviours. The concluding section examines the theoretical and practical implications of the study for academics and practitioners in a range of fields.

\section{Parenting, leisure and consumption}

Studies of parenthood and motherhood frequently suggest these are not fixed roles or identities; rather they are complex, negotiated constructions (cf., Maher, 2005; Miller, 2005; 2011; Neiterman, 2012). The notion of what it means to be a parent and how it should be performed are shaped by the settings in which they are experienced, the contextual relationships through which these notions of selves are constructed, as well as the various social, cultural and political discourses that shape expectations of parenthood (Collett, 2005; Heisler and Ellis, 2008; Miller, 2005; 2011). The articulation of parenthood involves the interaction of multiple desires and tensions, for example, of love and care for dependent children, alongside pressures to conform to particular ideals of parenthood, whilst balancing other societal, cultural and economic demands. In some contexts, these forces may complement each other, while at other times they may represent conflicting interests (Lee et al., 2014).

The contrasting stresses of parenthood have been highlighted in previous studies of mothers' leisure consumption. Specifically, research has stressed that women's leisure experiences are often inseparable from notions of work, due to the continuing intersection between recreation and responsibilities for various domestic duties and caring for children (Davidson, 1996; Larson et al., 1997; Shaw, 1992). It is possible to argue that such hazy distinctions between work and leisure are also evident during visits to hospitality venues. Moreover, this blurring may consequently influence what parents expect from the consumption experience, in terms of the environment, the services and the hospitality product, but it may also shape how parents and carers with accompanying children actually experience hospitality spaces.

As Lugosi (2010) noted, a few studies offer brief glimpses of parent and carer consumption, but they are limited in depth and do not offer detailed insights into their subjective experiences. For example, in their observational study, Laurier and Philo (2006) described how a woman with a stroller negotiated the café environment and how fellow diners helped distract the child when the female carer cleaned up a spillage. They did not however provide insights from the perspective of the people involved. Law (2000) is one of the few researchers to address the topic, but the focus of his research note was on the perceived managerial problems associated with breastfeeding in venues rather than the broader issues surrounding patronage and consumption. Moreover, no attempt was made to consider parents' or carers' perspectives.

More recently, Karsten et al. (2015) examined family leisure time in cafés, bars and restaurants. They considered the way entrepreneurs targeted families alongside the difficulties operators faced when catering for these market segments. Karsten et al (2015) also studied parents' and children's interactional routines, focusing largely on different patterns of sociality. However, they did not consider in any detail the broader 
hospitality dimensions of their consumer experiences, or how the practices and experiences of parenting/care-provision were shaped by hospitality elements.

Although there is a lack of hospitality-specific literature, there is a growing body of work examining the interaction of parenthood, motherhood and consumption (Carrigan and Szmigin, 2006; Thomsen and Sørensen, 2006; Johnstone and Todd, 2012), which may help to appreciate issues relevant to the study of parents/carers and their interaction with hospitality spaces. More specifically, research has examined how consumption practices help articulate notions of parenthood (Thomsen and Sørensen, 2006); consumption may facilitate parenting; but consumption also presents risks and anxieties as parents negotiate multiple motivations and responsibilities (The VOICE Group, 2010). Finally, and importantly for this study, existing work suggests that consumption spaces provide opportunities for escape and sociability, which again serve to negotiate the multiple challenges associated with parenthood (Johnstone and Todd, 2012).

The current study considers hospitality venues as particular spheres of consumption and seeks to examine how consumption in and of these venues is entangled with experiences of parenting and/or childcare provision. More specifically, the data are used to consider how hospitality spaces help parents/carers to negotiate the stresses of parenthood or care provision, and how patronage with a child or children shapes their experiences in these spaces. This, in turn, helps to better understand the construction and experience of parenthood/care provision as identity and practice. In order to do this, the next section considers the concept of hospitality.

\section{Hospitality as context and concept}

The notion of a hospitality venue is used here as a cover-all term for a number of experiential contexts including cafés, restaurants and bars. Although the product range and services of these operations vary considerably, all food and drink venues provide hospitality. Brotherton (1999: 168) suggests that hospitality can be defined as "a contemporaneous human exchange, which is voluntarily entered into, and designed to enhance the mutual wellbeing of the parties concerned through the provision of accommodation, and/or food, and/or drink". This conception stresses mutual wellbeing, which ignores asymmetries of power and the potential for repression in hospitality transactions; it also downplays the importance of social interaction in hospitality. A broader conception of hospitality is that it is fundamentally about gestures of welcoming and the creation of inclusive physical and symbolic spaces (Bell, 2007; Dikeç, 2002). Acts of hospitality often involve food, drink and other stimulants, including tobacco and legal or illegal drugs, alongside entertaining or engaging interaction as people create shared social spaces, although these elements are not always present. Mundane forms of hospitality, ie. food and drink provision in commercial environments, can be delivered with minimal or no interaction between staff and customers or between customers. Therefore, its provision in commercial spaces may not always involve embodied performances of hospitality or hospitableness. 
The production and consumption of hospitality implies the existence of a host provider and a receiving guest, each with obligations towards the other (Lynch et al., 2011). Hosts have duties to ensure the wellbeing of their guests, while guests must respect the rules of the host; both are subjugated to the hospitality transaction (Lynch et al., 2011). Within hospitality venues, operators are obliged to provide services, products and experiences as part of a commercial transaction, and consumers have responsibilities to observe the rules and to pay for the products, services and facilities. There is a danger that this suggests a reductive distinction between the provider and consumer, whereas hospitality, like all forms of social interactions are co-produced, not just between hosts and guest but also between guests (Lugosi, 2009). Moreover, this also stresses the social dimensions of hospitality experiences, which potentially ignores its material dimensions. In short, the environment in which hospitality is experienced and the material artefacts, for example, the furnishing and the foodstuffs, are also important to acknowledge when considering how spaces are experienced as either hospitable or inhospitable by particular consumers.

Finally, it is also important to avoid conceptualising hospitality narrowly as welcoming, inclusive or open, which implies it is a wholly positive set of actions. Practices of hospitality require guests/consumers to acknowledge their roles and responsibilities. Such ascription of status may (re)construct relationships of power. Even momentary gestures of inclusion involve decisions regarding who receives hospitality, when and on what basis, which involves processes of exclusion. Moreover, the manifestation of hospitality can reinforce social exclusion through the (re)production of hierarchies and social distinction. The question for the current study is how parenthood and care provision are enacted through hospitality transactions, within hospitality venues. We examine how commercial hospitality spaces become the sites where parenthood and care provision are performed. Importantly, we consider how the provision and reception of hospitality shapes how people experience parenthood/care-provision: ie. how these experiences offer opportunities for restorative consumption, socialisation, the reproduction of identities and cultural values, and the risks and stresses involved, including how these are negotiated.

\section{Methods}

The study draws on semi-structured interviews with 30 mothers, fathers and those involved in caring for children living in Australia and the United Kingdom (23 females and 7 males; see Table 1 for details of the sample). After gaining ethics approval from the respective universities, participants were contacted through a number of channels including postings to parent-centric websites such as netmums.co.uk and the use of pre-existing university databases of potential participants. In addition, visits were made to playgroups and play centres, flyers were distributed at a UK school in the [location deleted for review purposes] area and in Australia a radio interview was used to recruit participants. The study adopted a nonprobability, purposive sampling approach, combining criterion and pro-active snowball techniques (Patton, 2002). The principal criterion for inclusion was patronage of 
hospitality venues with children. The invitation emphasised that we also wished to talk with parents and carers who did not go to hospitality venues regularly with children in order to ascertain their attitudes. The aim was not to obtain a generalisable sample; nor to conduct a comparative analysis of Australian and UK parenting cultures; rather we sought heterogeneity in the sample with which to explore a variety of experiences. We did not enquire about relationship status and sexuality, although several participants self-identified as single and/or separated mothers and fathers, and one was part of a lesbian relationship. The sample also had considerable cultural and ethnic diversity with participants of various mixed heritage including Azerbaijani, German, Italian, Indian, Mexican and Zambian. However, we acknowledge that the sample had a greater number of participants with further and higher education qualifications and we recruited more female than male participants. Moreover, despite our attempt to recruit people who did not visit venues, we only have one such contributor and the experiences of non-participants, including the reasons for their (non)consumption, deserves further consideration.

Insert Table 1. about here

Interviews were conducted in locations convenient to the participants. These included restaurants, cafés, participants' homes and gardens, university offices and rooms, and several were conducted via telephone or Skype. Several mothers brought children with them to interviews. Interviews lasted for approximately 1 hour and explored patterns of patronage including positive and negative experiences, and operational issues including the design and layout of specific venues, products and services. All the interviews were recorded, with the permission of the participants, and were transcribed by a third party.

There was an element of concurrent data collection and analysis (see Lofland, 2006), which enabled the researchers to revise both the interview content and approach in light of emerging themes and issues. For example, the issue of noise emerged during initial interviews and we explored this emergent theme in subsequent ones. The transcripts were analysed thematically (Braun and Clarke, 2006) by three researchers working in parallel. Coding and identifying emerging issues separately, and subsequently bringing the three interpretations together acted as a form of 'researcher triangulation' (Denzin, 2009), reinforcing points of agreement, while highlighting areas of difference in interpretation.

The development of an interview guide, based on the literature and our initial consideration of relevant issues meant the analysis utilised a number of pre-existing sensitising concepts, akin to template analysis (King, 2004): the use of existing codes to which we added new codes as they emerged through analysis. These were condensed into higher-level themes through an iterative process. 


\section{Findings and discussion}

\section{Hospitality and/as socialisation}

Previous research has pointed to the interaction of space, materiality and parenting, in terms of opening new possibilities for, and placing limitations on, experiences of parenthood. Spaces may become exclusionary and inhospitable for some parents, for example during breastfeeding (Longhurst, 2007), while acting as welcoming spaces of consumption for others (Johnstone and Todd, 2012). Participants in this study pointed to the multiple ways in which patronage with their children was embedded into parenting and visits became part of the child's socialisation into social and cultural norms. For example:

I have always been very proud of the fact that he isn't the sort of child who will only eat cheese and chips and nothing else. He's been exposed to a huge range of food through being taken out to eat. He will always try something new, he won't necessarily be polite about it, but he will try it. He has got defined tastes and they are eclectic and I'm really proud of him for that, he's got reasonable table manners, and I enjoy watching him being really enthusiastic about things. ... I think I also like the fact that people have come up to us and said what lovely table manners he has ... and he's got compliments from waiters and things, about how well he can order food, and so I think that's a skill that's worth having. (Nicola)

This extract illustrates multiple modes of connectedness shaping parenting experiences: first, more broadly, between the hospitality space, with all its normative associations, and parenthood; second, between the parent and child's consumption and the perceptions of their behaviours by third parties; and third, between the child's behaviour and self-conceptions of parenthood. In highlighting these modes of connectedness, Nicola's observations implicitly reference discourses of good parenthood (cf. Collett, 2005; Tardy, 2000) insofar as her child's capabilities were conceived as performances of appropriate habitus and cultural capital (Bourdieu, 1986). Other participants in the study made similar overt references to the importance of hospitality venues for the development of cultural competencies. For example:

And to be honest now, when he's older, I go there because I think kids need to know as well how to behave in coffee places, I think it's confidence building as well, that he goes to get more milk for mum's coffee, or he will go and say, 'Can I buy that biscuit?' Or he will go and get his food, because he knows where it's at, he can communicate with a grown-up and he knows to be friendly, loud enough, polite ... I think that's quite good for the children, and how to behave, not to be noisy, not to knock stuff over, so it's a bit of a learning curve I think. (Brigitte) 
The ability to receive, consume and effectively perform being an appropriate guest in hospitality may also become part of socialisation at much earlier stages. For example, Nicola noted that taking her son to a venue facilitated her child's development:

Yes, in the noodle place. He would have been about seven months old ... and yeah, he was not really eating much solid food at that point, and all of a sudden here was something he could be really enthusiastic about, and the place itself was very welcoming. They had proper high chairs that clipped onto a table, that were wonderful, they didn't treat him like he was an inconvenience, which some places can do, and it suddenly opened up a, 'Hey I can actually go out and do things with this baby,' you know, which was wonderful. (Nicola)

Furthermore, finding a space that facilitated this type of socialisation within a broader inclusive experience enabled Nicola to feel a sense of freedom and mobility. This again reinforces the multiple impacts that hospitality provision can have on the child, the parent and the overall experience of parenthood.

\section{Hospitality as relief from parenting}

A number of researchers have explored the restorative nature of consumption in hospitality venues (Glover and Parry, 2009; Rosenbaum, 2009), arguing that the positive effects of the environment and opportunities for socialising help enhance the wellbeing of the elderly and long term ill. Similarly, participants in this study pointed to the important role that hospitality venues played at multiple stages in parenthood. In some cases, visits included their children, for example:

Before he was in nursery, so before he was three, I tried to come into town as often as I could, mostly because it was doing my head in, being at home with small toddlers! ... It was a kind of imperative in my day that I got out and did something social, apart from anything else because I was on crutches at the time as well, which meant that if I didn't come out with the baby, I didn't come out at all. (Nicola)

Parenthood changes both the scope and nature of mobility (Bell and Ribbens, 1994; Murray, 2008). Parenthood and the responsibility of childcare-provision may reconfigure social relationships and networks, but the physical challenges of movement with children, transport, time and economic resource constraints as well as perceptions of risk shape where parents can go, with and without their children. In this participant's case, hospitality venues were thus important in overcoming potential immobility and isolation. However, this was not a unique observation. Many of the participants talked about visits to hospitality spaces contrasting with everyday spaces. 
I get a bit of respite, especially when running to work, running to the school, sprinting here, sprinting there, it's just nice sometimes after school to say, 'Do you know what, let's go there.' And I can hear about his day, he can play a little bit, we can snack, it's like an hour's holiday in the day; because you don't get it a home. At home the washing's staring at you, wants to be done. You know you should be doing this and that. Because you're not a home if you've got that luxury of that little window, where it's OK to do nothing, and you can sit there with your child in a way that there aren't toys, there isn't a telly, it's just you and him, and it's very grown up. (Brigitte)

These descriptions of hospitality suggest that it becomes a form of reward, which may serve to counteract the contemporary 'intensification of parenting' (Lee et al., 2014). Hospitality spaces may have facilitated a greater sense of reconnection between parent and child; however, in other respondent's narratives, hospitality loosened the parent-child connection, thus offering temporary re-articulation of parental responsibility.

I think to be honest for me, it's almost just like rest, because it's somewhere where the boys are generally entertaining themselves, so I feel relaxed because you're not having to police them or anything like that. And McDonald's is a place where everything is absolutely full of kids, so therefore I don't have to feel paranoid about anyone else, so I'm not anxious or annoying anybody else, or I have to keep the boys silent because other people might get annoyed. So for me it's quite relaxing to go there because that's what McDonald's is made for, it's made for kids, and it gives me 20 minutes when I can possibly read the paper and not worry. (Anna)

It is interesting to note in the previous two extracts that the differences in the 'propositions of hospitality' (Lugosi, 2009) facilitate alternative experiences of consumption and parenthood. Where a venue is perceived to be less constraining regarding normative expectations about behaviours, including, for example, noise or what may be termed 'acceptable deviance', parents may be more likely to conceive it as escape from parental pressures.

For some parents, visits to hospitality venues without their children represented a clearer break from the normal routines and pressures of parenting. However, it is still important to note how these moments of pleasure and potential restorative qualities were still framed in relation to parenting responsibilities and the performance of acceptable parenthood.

And so I would do that once a week, on the days that I could take Jamie up to nursery for eight, eight thirty, and then I would ... go and sit in Café Nero with a coffee or whatever and wait for things to open 
up and then go about my day. ... It was a very relaxed place to do that, to sit there by myself and not feel weird or fed up if I'm just sitting there by myself, sometimes staring into space! (Chloe)

\section{Hospitality and the enactment of 'good parenting'}

A substantial body of work has considered how the embodied, performative nature of parenthood creates particular subjectivities in parents and thus subjective experiences of spaces (cf. Atkins, 2009; Collett, 2005; Longhurst, 2005; Madge and O'Connort, 2005; Miller, 2011). The extracts introduced in the previous section reflect how notions of parenthood were articulated through and thus mediated by parents' and carers' experiences of hospitality. Expanding on this theme, this section considers how experiences of hospitality were shaped by the enactment of discourses of 'good parenting'. Venues blurred the division between private and public space, which reinforced the visibility of parenting. Parenting was enacted through the production and consumption of hospitality. Several parents pointed to their concerns about the foods and drinks available in venues, and how these shaped their consumption choices. For example:

What I can search there for my child to eat and drink, is stuff that I would give him at home, stuff that's good for him, it's not, 'Oh my God, all they have is bubble gum drink, so you better have it.' It's not like that. I'm happy and I know he will enjoy it and it will be good for him. (Brigitte)

Beyond concern regarding the food and drink available for their children, many of the parents in this study were mindful of their children's moods and behaviours, which then shaped their consumption choices and their own experiences. Participants frequently commented that they were conscious of how their child's behaviour was perceived by other patrons and how these subsequently affected the parent's consumption.

I'm aware of when he begins to cry or gets a bit tired, I'm aware of how I used to be as a non-parent, and I remember thinking 'god'. When you get on the plane and avoid the area where all the kids are, 'cause you think I don't want to sit anywhere near all the families. And I remember being that person who went out to cafés and restaurants and just thought 'my god there's a screaming child and now I have one!' I find myself thinking 'god, poor parent', because you just know that their nerves are shattered and they've been up all hours. So no, not really, but I am just aware that maybe it might be for other people, that they might find it irritating and they just don't understand. I didn't used to understand. (Karen) 
Ensuring their child's wellbeing thus ensured that parents gained a greater level of satisfaction from patronage. This was expressed by other parents too:

The other thing is that it's relaxed, because the minute you feel you should behave and your child should behave, you feel tense and you're not going to enjoy your time. So it's the whole thing about how they make you feel and how child friendly they are. I think that's a big part actually, because you know what it's like when you go with a child somewhere, you just feel, 'Oh we shouldn't have come.' Or, 'I'm so sorry I'm a mother,' a bit like that, and then you think, 'Right, that's it, we're not coming here again.' (Brigitte)

Drawing on Goffman's (1969) dramaturgical analysis, Miller (2014) and Collett (2005) noted that parenthood can be thought of as 'impression management' with inherent risks if its performance is perceived to be deficient. Many of the interviewees were conscious of these risks to self, but they also showed a conscious resilience, for example, persisting in the face of co-customer sanctions:

...we had to wheel [the pram] through. One particular gentleman was there with his wife and I said 'excuse me' about three times - he just had to move his chair a small amount and he just sort of looked down his nose at me ... so it sort of put you a little on edge but we stayed. (John)

Parents' and carer's consciousness of children's behaviour and wellbeing suggest particular notions of embodiment in their connection of parenthood, consumption and hospitality. In her phenomenological examination of breastfeeding, Simms (2001) conceptualises the bond between mother and child as 'chiasmic', arguing that their existence can be understood to become non-dualistic or intercorporeal. Arguably, our participants' accounts of parental experiences in hospitality demonstrate a different but related form of intercorporeality. Parents and carers (male and female) are no longer singular agents, but appear to be connected to their children, through their behaviours and interactions with other patrons. More specifically, children can be conceived as being extended bodies of their parents. The children's voices, limbs and their actions have consequences for the parent and their experience of hospitality. Furthermore, hospitality spaces and the consumption of hospitality amplified this intercorporeality in a number of ways. Firstly, hospitality venues facilitate co-presence alongside mutual awareness between parents or carers, children in their care, staff and other patrons. Secondly, this co-presence is also tied to food, drink and hospitality related actions that require certain forms of embodied cultural competencies, for example the ability to sit still, eat or drink, and not disturb others. The performance of these competencies shapes mutual awareness and the ongoing acceptability of copresence. 


\section{Hospitality and children's power}

As demonstrated above, the enactment of parenthood in the visible, public domain of commercial hospitality presented a series of risks. Participants also highlighted children's ability to present, amplify and manage risks. Narratives repeatedly emphasised that the wellbeing of the child, and the potential for the child to determine the nature of the experience, also shaped their choice of venues, and effectively extended to whether they would visit any hospitality venue.

I would not go to a very fancy restaurant with a child, because I wouldn't really enjoy my meal. And we noticed that at the weekend when we took her out - I could have been eating a piece of cardboard because you're just more focussed on 'is she eating her food', 'is she going to start kicking off'. (Jo)

Academics increasingly emphasise the importance of children's agency (Holloway and Valentine, 2000), and recognise their ability to exercise power in food-related behaviour (Carrigan et al., 2006; Grieshaber, 1997). The participants in this study illustrated that the parent/carer-child interaction had significant impacts on their consumption choices in terms of the places they visit/avoid, but also the times at which they can patronise venues and even the services they avail themselves of and those they do not.

They like McDonald's, but I try not to take them there all the time, because it's not the best sort of food. They like the playground and they're familiar with the characters and the marketing is very strong and it's hard for them not to really be attracted to that...But I suppose even if I do go to McDonald's I can still get the salads and the fruit... alternatively I pack food for them (Hassan)

...the child's needs and the situation that you're in when you've got a child is perhaps slightly above the things that used to be important. I wouldn't for instance have gone to Costa in the past, unless there was a very good reason, because I don't particularly agree with that kind of ... I don't like that kind of place, I don't support those kind of 'brandy' places, but now that I have a child I do sometimes have to go there because it's the only option. (Jo)

Bound up in these reflections are the re-emerging discourses of 'good parenthood' (cf. Goodwin and Huppatz, 2010; Lee et al., 2014), implying a sense of sacrifice and the prioritisation of their child. This may have emerged through specific hospitality consumption practices when parents capitulated to the whims of children:

Well, he used to insist on being part of the ordering process and order his own babyccino, which got complicated when he started 
ordering a big-babyccino and no-one knew quite what that was, but he just thought 'I'm not a baby, so that menu item no longer applies'. (Karina)

However, children's ability to influence parents' choices and mobilities were also determined by more embodied experiences or performances of parenthood. Other accounts suggest pragmatic explanations of parents' choices of venues, for example the necessity for the children to eat or sleep, which were managed alongside the desire to interact in networks:

Yeah, we would often, if I meet a friend at the women's group, we would then go to a café afterwards, or we'd go to lunch, l've met other mums on different days when we've met up and gone to lunch and cafés and gone for a coffee. Sometimes lunch, it depends when you fit food in around feeding, changing the baby. (Karen [emphasis added])

\section{Hospitality, risk and coping behaviours}

Many accounts of parenthood, particularly women's experiences of pregnancy and breastfeeding, highlight how the challenges associated with parenting and care provision outside of the home are managed (cf. Lane, 2005; Longhurst, 2001). Our narratives also showed that beyond the choices of venue, and the temporal aspects of patronage, the entanglement of parenthood and hospitality involved a series of coping behaviours to help negotiate the experience. Consuming as a parent included service substitution - compensating for anticipated service failures and service shortfalls. As Karen noted:

I now take hot water with me if I'm going anywhere, so I've had to adapt, and just think, 'Right I can take my own hot water,' and be a bit more organised and a bit more prepared, because not everyone's prepared to give me hot water. (Karen)

Importantly, several respondents noted that consumption and performances of parenthood were not limited to the provision of food and drink alone. For example, Adele observed:

You're going through the phase as all parents do of having the entertainment pack with you, so you bring the cards. We used to put a pack of cards in our bag, so we'd play cards a lot, the drawing stuff, but the drawing stuff gets a bit boring after a while, but then you go through the phase of having the Nintendo DS that comes out. ... But when they're very small, it's the pass the credit cards around the table, so here's one for you, pass it to dad ... the main making up one is the hide something from the table. (Adele) 
Consuming as a parent or carer also influenced which spaces they inhabited and how. For example, the extracts below demonstrate how parents and carers gauged which would be appropriate discrete spaces for them and the children in their care, and how they considered other patrons when performing caring duties.

I suppose it's in the back of my mind that some people don't agree with breastfeeding in public because you see it on the news all the time... I was fully covered up, didn't give any reason to 'perv' at me or whatever... I'd probably pick a really comfortable corner that I could go into and kind of hide. (Rosa)

Quite often I'm thinking of where you sit, looking for places that are in a corner that might have a bit of space where the children can get down and run around and not be interfering with other people who are using the restaurant, café, whatever, so that's the kind of things that would weigh into where we'd choose. (Helen)

Consuming hospitality with children inevitably involved tensions, where actual behaviours deviated from those expected in a particular venue, which resulted in parents/carers departing from venues or avoiding venues in anticipation of conflicts or judgements from others about their performances of parenthood.

If people make you feel bad about being there, and you're depressed, it's frightening actually. And that did happen quite a bit initially, because I was going to the wrong places I suppose ... and so I was terrified. I would literally run out of places with him. (Martine)

I would hesitate to take him to a very posh restaurant too late at night, because you do get the huffing and puffing of, 'That child should be in bed,' and it's like, 'You don't know our routine and you don't know my child, but at the same time, I'm not really wanting to deal with your disapproval'. (Nicola)

In all these situations, hospitality, and the possibilities for experiencing hospitality or inhospitality shaped, and were shaped by, both the discourses of parenthood and the actual embodied experience of parenthood. Parents' and carers' sense of risk associated with specific venues subsequently informed their choices of venues. A parallel can be drawn here between participants' narratives and those in Skeggs' (1999) work on women in gay spaces. Skeggs (1999) argued that heterosexual women patronised gay venues because they were not subjected to the heterosexual male gaze and associated sexual harassment: they became 'invisible' in these spaces. As one interviewee noted when asked about important features of venues he would visit with his child: "quite high noise levels, which is actually quite good with kids, you don't have to worry about the occasional cry or whinge or whatever." (Adam). Many of 
the parents and care-providers noted that they chose venues that were noisy, where they could become 'inaudible', thus avoiding scrutiny and negative judgment by other patrons of their children and of them as care providers.

\section{Conclusion}

This paper has explored the multidimensional entanglement of parenthood, care-provision and hospitality. It has demonstrated how the spaces and practices of commercial hospitality provision can support parenthood, alongside the way parenthood, and child-parent-consumer-provider interactions shape parents' and carers' experiences of hospitality. Hospitality venues provide contexts for care provision, acting as spaces of sociality, while also offering escape from the stresses of parenting. Participating in hospitality experiences potentially sensitises children regarding social and cultural norms, and thus informs their socialisation. However, parents' narratives also reinforce the duality of hospitality experiences, and the multiple forms of emotional and physical labour carers must mobilise. These accounts also point to children's agency and how parents' attention to children's wellbeing visà-vis hospitality shapes parental experiences. Finally, we identified parents' performative responses and coping behaviours as they ensured positive experiences or compensated for negative ones.

It is important to acknowledge what could be termed the class-dimensions of the study and its emerging findings. In discussing their values, aspirations and anxieties, the parents and carers in this study reproduced notions of middle-class identity and habitus. This stems in part from the sample in which respondents with higher educational qualifications are overrepresented. However, it is also useful to stress that such class values may effectively become a core aspect of hospitality venues' commercial propositions. The ability to consume is determined by parents'/carers' ability to mobilise both economic and cultural capital. Consequently, the expanding marketisation of family consumption and the targeting of carers and parents by operators may lead to further intensification of parenting. Spaces of hospitality are visible social domains where class aspirations are (re)produced and anxieties are perpetuated (Miller, 2014). Venues may therefore also reproduce class inequalities and serve to enact forms of class-based social inclusion and exclusion.

Such class-based tensions may lead to the conclusion that hospitality spaces offer a mixed set of experiences for their patrons. Nevertheless, the findings highlight that we should consider more carefully the role of hospitality venues within parental geographies and practices. If, as we have argued, these spaces have a positive function in supporting parenthood, and a transformative potential to positively shape parent and child experiences, this study suggests that hospitality practitioners should be sensitised further regarding the needs and practices of those involved in childcare.

Arguably, operators may simply be driven by a commercial imperative, but they may actually appreciate the social, cultural and moral dimensions of hosting these consumers. Regardless of their motivation, creating inclusive environments and responsive services have a number of benefits for organisations and their consumers (Rosenbaum, 2009). There are undoubtedly commercial risks and opportunities 
involved in hosting parents and carers with children. Alienating such consumers can result in a public backlash and has reputational risks for organisations (Lugosi, 2010), particularly with the prevalence of social media. Moreover, creating satisfactory experiences for parents, carers and the children in their care may also ensure the satisfaction of other patrons for whom children and families represent experiential threats.

Market researchers continue to gather data on family consumption habits, but this study helps to give voice to the emotional and practical dimensions of their experiences, which is often absent from market research reports. Sensitising practitioners may thus rely on communicating the physical, emotional and psychological labours of consuming as a parent or carer. Encountering such personal accounts can be the first step in developing greater responsiveness to parents', carers' and children's needs regarding factors that may enhance their experience or cause dissatisfaction. The emerging themes of this study may, however, be condensed into a toolkit for practitioners.

A cynical response to such attempts to sensitise practitioners is that it perpetuates the commodification and marketisation of parenting, care-provision, and childhood more generally. However, understanding the work of parenting, through the provision and consumption of hospitality, is also of benefit to non-commercial organisations, which support parents and care-provision. Specifically, if hospitality does indeed facilitate a series of positive benefits, public health practitioners should also be made aware of its potential to influence parental experiences (cf. Wu et al., 2013). Previous studies have pointed to the importance of social contacts for mothers suffering from post-natal depression (Mauthner, 1995). Hospitality can be utilised in the promotion of wellbeing of mothers, carers and the children in their care. Understanding the gestures of (in)hospitableness and its material dimensions can also help to develop inclusive, non-commercial social spaces, for example in the form of play centres and venues hosting neonatal support networks.

Concerning future research, this study has shown how examining further parents' and carers' experiences can help us to develop a more nuanced understanding of parenthood and the geographies of care-work more generally. This includes the identity constructions and the embodied relationships involved in parenting and caring, and their interactions with the practices of hospitality. Future research building on this study can thus explore further how a wide range of commercial and non-commercial leisure spaces are made (in)hospitable.

\section{Acknowledgements}

We would like to thank Tina Miller and the reviewers for helpful comments on earlier versions of this article. We are also grateful to the parents and carers who contributed to this study and to Oxford Brookes University for providing financial support for the project. 


\section{References}

Aitken, S. C., (2009), The Awkward Spaces of Fathering, Farnham: Ashgate.

Bell, D., (2007), 'The hospitable city', Progress in Human Geography, 31(1): 7-22.

Bell, L. and Ribbens, J. (1994), 'Isolated housewives and complex maternal worlds-The significance of social contacts between women with young children in industrial societies', The Sociological Review, 42(2): 227-262.

Bourdieu, P., (1986), Distinction, London: Routledge.

Braun, V. and Clarke, V., (2006), 'Using thematic analysis in psychology', Qualitative Research in Psychology, 3: 77-101.

Brotherton, B., (1999), 'Towards a definitive view of the nature of hospitality and hospitality management', International Journal of Contemporary Hospitality Management, 11(4): 165-173.

Carr, N., (2011), Children's and Families' Holiday Experiences, Abingdon: Routledge.

Carrigan, M. and Szmigin, I., (2006), 'Mothers of invention': Maternal empowerment and convenience consumption', European Journal of Marketing, 40(9/10): 11221142.

Carrigan, M., Szmigin, I. and Leek, S., (2006), 'Managing routine food choices in UK families: The role of convenience consumption', Appetite 47(3): 372-383.

Collett, J. L., (2005), 'What kind of mother am I? Impression management and the social construction of motherhood', Symbolic Interaction 28(3): 327-347.

Davidson, P., (1996), 'The holiday and work experiences of women with young children', Leisure Studies, 15: 89-103.

Denzin, N., (2009), The Research Act, 3rd edn, Piscataway, NJ: Transaction.

Dikeç, M., (2002), 'Pera peras poros: Longings for spaces of hospitality', Theory, Culture and Society, 19: 227-247.

Glover, T. D. and Parry, D. C., (2009), 'A third place in the everyday lives of people living with cancer: Functions of Gilda's Club of greater Toronto', Health and Place, 15(1): 97-106.

Goffman, E., (1969), The Presentation of Self in Everyday Life, Harmondsworth: Penguin. 
Goodwin, S. and Huppatz, K., (2010), The Good Mother, Sydney: SUP.

Grieshaber, S., (1997), 'Mealtime rituals: Power and resistance in the construction of mealtime rules', British Journal of Sociology, 48(4): 649-666.

Heisler, J. M. and Ellis, J., (2008), 'Motherhood and the construction of "mommy identity": Messages about motherhood and face negotiation', Communication Quarterly, 56(4): 445-467.

Holloway, S. and Valentine, G., (eds), (2000), Children's Geographies, London: Routledge.

Johnstone, M.-L. and Todd, S., (2012), 'Servicescapes: The role that place plays in stayat-home mothers' lives', Journal of Consumer Behaviour, 11: 443-453.

Karsten, L., Kamphuis, A. and Remeijnse, C., (2015), "Time-out' with the family: The shaping of family leisure in the new urban consumption spaces of cafes, bars and restaurants', Leisure Studies, 34(2): 166-181.

King, N., (2004), 'Using templates in the thematic analysis of texts', in Cassell, C. and Symon, G. (eds), Essential Guide to Qualitative Methods in Organizational Research, 256-270, London: Sage.

Lane, R., (2014), 'Healthy discretion? Breastfeeding and the mutual maintenance of motherhood and public space', Gender, Place and Culture, 21(2): 195-210.

Larson, R., Gillman, S. and Richards, M., (1997), 'Divergent experiences of family leisure: Fathers, mothers, and young adolescents', Journal of Leisure Research, 29(1): 78-97.

Laurier, E. and Philo, C., (2006), 'Cold shoulders and napkins handed: Gestures of responsibility', Transactions of the Institute of British Geographers, 31(2): 193208.

Law, R., (2000), 'Breastfeeding in public: Should this be allowed in hotels?', International Journal of Hospitality Management, 19: 89-92.

Lee, E., Bristow, J., Faircloth, C. and Macvarish, J., (2014), Parenting Culture Studies, Houndmills: Palgrave Macmillan.

Lofland, J., (2006), Analyzing Social Settings, 4th edn, Belmont, CA: Wadsworth.

Longhurst, R., (2005), '(Ad)dressing pregnant bodies in New Zealand: Clothing, fashion, subjectivities and spatialities', Gender, Place and Culture, 12(4): 433-446. 
Longhurst, R., (2007), Maternities, Abingdon: Routledge.

Lugosi, P., (2009), 'The production of hospitable space: Commercial propositions and consumer co-creation in a bar operation', Space and Culture, 12(4): 396-411.

Lugosi, P. (2010), 'Women, children and hospitable spaces', The Hospitality Review, 12(1), 31-38.

Lynch, P., Germann Molz, J., McIntosh, A., Lugosi, P. and Lashley, C., (2011), 'Theorising hospitality', Hospitality and Society, 1(1): 3-24.

Madge, C. and O'Connort, H., (2005), 'Mothers in the making? Exploring liminality in cyberspace', Transactions of the Institute of British Geographers, 30: 83-97.

Maher, J., (2005), 'A mother by trade: Australian women reflecting mothering as activity, not identity', Australian Feminist Studies, 20(46): 17-29.

Mauthner, N. S., (1995), 'Postnatal depression: The significance of social contacts between mothers', Women's Studies International Forum, 18(3): 311-323.

Miller, T., (2005), Making Sense of Motherhood, Cambridge: Cambridge University Press.

Miller, T., (2011), Making Sense of Fatherhood, Cambridge: Cambridge University Press.

Miller, T., (2014), 'Engaging with the maternal: Tentative mothering acts, props and discourses' in O'Donohoe, S., Hogg. M., Maclaran, P., Martens, L. and Stevens, L. (eds), Motherhoods, Markets and Consumption, 159-170, London: Routledge.

Mottiar, Z. and Quinn, D., (2012), 'Is a self-catering holiday with the family really a holiday for mothers? Examining the balance of household responsibilities while on holiday from a female perspective', Hospitality and Society, 2(2): 197-214.

Murray, L., (2008), 'Motherhood, risk and everyday mobilities', in Uteng, T. P. and Creswell, T. (eds), Gendered Mobilities, 47-63, Aldershot: Ashgate.

Neiterman, E., (2012), 'Doing pregnancy: Pregnant embodiment as performance', Women's Studies International Forum, 35: 372-383.

Patton, M. Q., (2002), Qualitative Research and Evaluation Methods, 3rd edn, London: Sage. 
Rosenbaum, M. S., (2009), 'Restorative servicescapes: Restoring directed attention in third places', Journal of Service Management, 20(2): 173-191.

Schanzel, H., Yeoman, I. and Backer, E., (eds), (2012), Family Tourism, Bristol: Channel View.

Shaw, S. M., (1992), 'Dereifying family leisure: An examination of women's and men's everyday experiences and perceptions of family time', Leisure Sciences, 14: 271286.

Simms, E.-M., (2001), 'Milk and flesh: A Phenomenological reflection on infancy and coexistence', Journal of Phenomenological Psychology, 32(1): 22-40.

Skeggs, B., (1999), 'Matter out of place: Visibility and sexualities in leisure spaces', Leisure Studies, 18(3): 213-232.

Tardy, R., (2000), "But I am a good mom': The social construction of motherhood through health-care conversations', Journal of Contemporary Ethnography, 28: 433-73.

The VOICE Group, (2010), 'Motherhood, marketization, and consumer vulnerability', Journal of Macromarketing, 30(4): 384-397

Thomsen, T. U. and Sørensen, E. B., (2006), 'The first four-wheeled status symbol: Pram consumption as a vehicle for the construction of motherhood identity', Journal of Marketing Management, 22(9-10): 907-927.

Wu, Z., Robson, S. and Hollis, B., (2012), 'The application of hospitality elements in hospitals', Journal of Healthcare Management, 58(1): 47-62. 
Table 1 Sample details

\begin{tabular}{|c|c|c|c|c|c|c|c|}
\hline Name & Gender & Age & $\begin{array}{l}\text { Highest Level } \\
\text { of Education }\end{array}$ & $\begin{array}{l}\text { Number of } \\
\text { children }\end{array}$ & Age(s) & $\begin{array}{l}\text { Visitor } \\
\text { Behaviour }\end{array}$ & Sample Group \\
\hline Adam & $M$ & $55+$ & PG & 1 & 12 years & $\begin{array}{r}>1 \text { per week/1 } \\
\text { per week }\end{array}$ & UK \\
\hline Nicola & $F$ & $35-44$ & PG & 1 & 9 Months & $\begin{array}{r}>1 \text { per week } / 1 \\
\text { per week }\end{array}$ & UK \\
\hline Adele & $F$ & $45-54$ & PG & 1 & 14 years & $\begin{array}{r}>1 \text { per week/1 } \\
\text { per week }\end{array}$ & UK \\
\hline Karen & $F$ & $35-44$ & PG & 1 & 7 Months & $\begin{array}{r}>1 \text { per week/1 } \\
\text { per week }\end{array}$ & UK \\
\hline Martine & $F$ & $35-44$ & PG & 1 & 2 Years & $\begin{array}{r}>1 \text { per week } / 1 \\
\text { per week }\end{array}$ & UK \\
\hline Helen & $F$ & $35-44$ & PG & 2 & $\begin{array}{l}3 \text { years } \\
6 \text { Years }\end{array}$ & 1-2 per month & UK \\
\hline Chloe & $F$ & $35-44$ & Higher & 1 & 2.5 Years & 1-2 per month & UK \\
\hline Brigitte & $F$ & $35-44$ & Higher & 1 & 6 Years & $\begin{array}{r}>1 \text { per week } / 1 \\
\text { per week }\end{array}$ & UK \\
\hline Anna & $F$ & $45-54$ & Higher & 2 & $\begin{array}{l}5 \text { Years } \\
6 \text { Years } \\
\end{array}$ & 1-2 per month & UK \\
\hline Amanda & $F$ & $35-44$ & PG & 2 & $\begin{array}{l}4 \text { Years } \\
7 \text { Years }\end{array}$ & $\begin{array}{r}1-2 \text { per } 3 \\
\text { months }\end{array}$ & UK \\
\hline Jo & $F$ & $25-34$ & PG & 1 & 19 Months & $\begin{array}{r}>1 \text { per week/1 } \\
\text { per week }\end{array}$ & UK \\
\hline Henri \& Paul & $M \& F$ & $35-44$ & Higher & 2 & $\begin{array}{l}4 \text { Years } \\
5 \text { Years }\end{array}$ & $\begin{array}{r}>1 \text { per week/1 } \\
\text { per week }\end{array}$ & UK \\
\hline Rosa \& Greg & $M \& F$ & $35-44$ & Higher & 4 & $\begin{array}{l}7 \text { Months } \\
5 \text { Years }\end{array}$ & $\begin{array}{r}>1 \text { per week/1 } \\
\text { per week }\end{array}$ & Australia \\
\hline
\end{tabular}




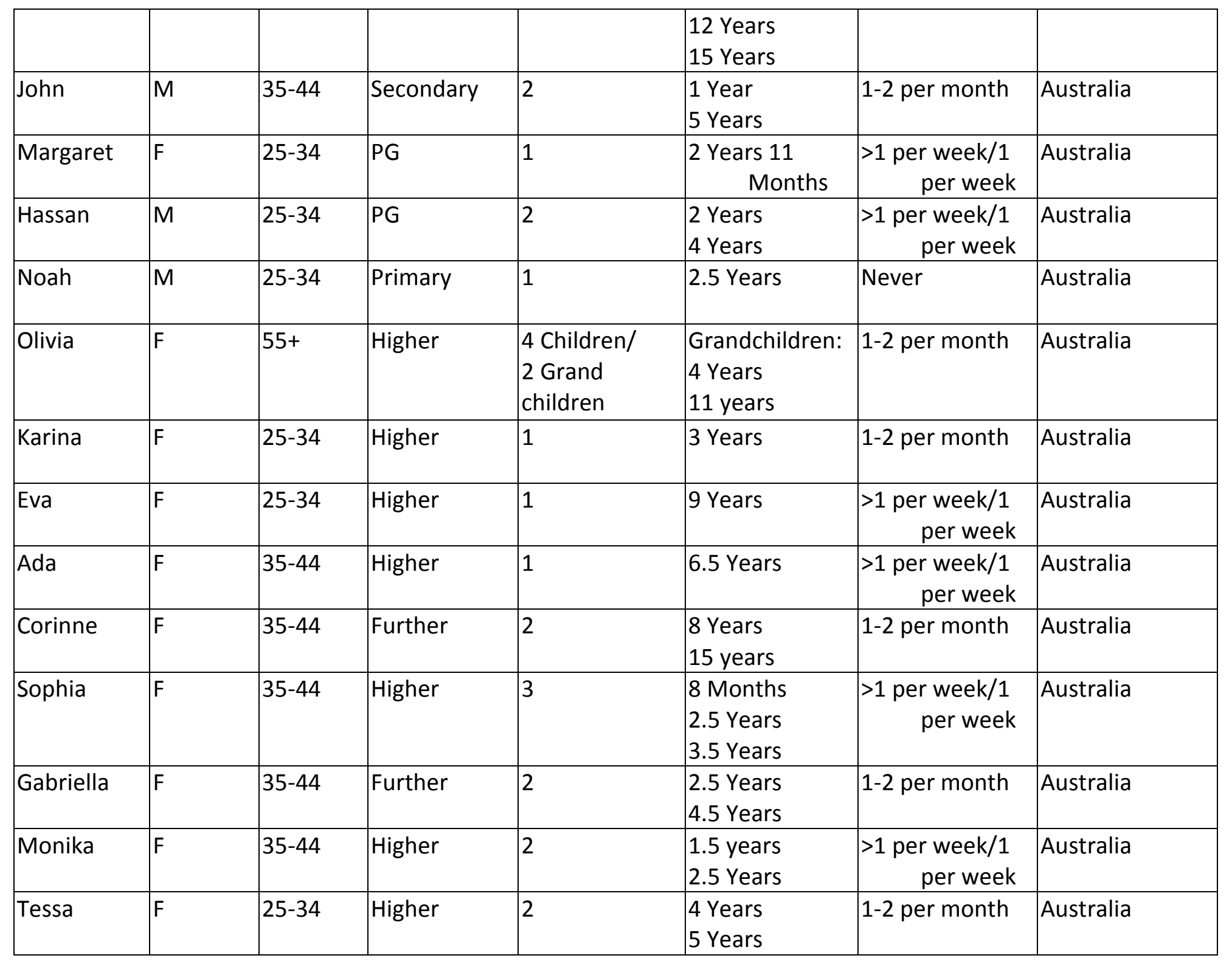




\begin{tabular}{|l|l|l|l|l|l|l|l|}
\hline Adrian & M & $25-34$ & Higher & 2 & $\begin{array}{l}3 \text { Years } \\
3 \text { Years }\end{array}$ & $\begin{array}{r}>1 \text { per week/1 } \\
\text { per week }\end{array}$ & Australia \\
\hline Sara & F & $35-44$ & Further & 3 & $\begin{array}{l}5 \text { Years } \\
8 \text { Years } \\
13 \text { Years }\end{array}$ & $1-2$ per month & Australia \\
\hline
\end{tabular}

